\title{
EDUCAÇÃO DO CAMPO E À DISTÂNCIA: ANTAGONISMO ABERTO NA LUTA PELA LIBERTAÇÃO*
}

Sara Ferreira de Almeida

\section{Introdução}

Esse ensaio traz reflexões em torno da importância do ato de lutar pela produção enraizada de conhecimento no campo da educação, especialmente em tempos de pandemia que coloca sob risco seu elemento substancial - a práxis. O argumento central do texto se apoia na teoria pedagógica freireana e dusseliana sobre o processo do conhecimento, cuja premissa é que: é impossível pensar seriamente em sua construção, "sem tomar em consideração os excluídos" (DAMKE, 1995, p. 13). A partir daí, traz à baila o debate crítico em torno das soluções que têm surgido para a educação no Brasil - antes, durante e pós pandemia - especialmente a que se refere à Educação à Distância (EaD). Para concluir, toma como foco de análise nesse cenário, a Educação do Campo que, pautada nos pressupostos da Pedagogia da Libertação, historicamente, forma sujeitos para que sejam capazes de levar adiante a luta pela reforma agrária e pelo fortalecimento de uma concepção e uma práxis educativa libertadora.

Sintetiza Enrique Dussel na obra "Ética Comunitária" que, em sentido estrito, práxis significa "o ato humano que se dirige a outra pessoa humana; ato em direção a outra pessoa e a própria relação de pessoa a pessoa" (DUSSEL, 1987, p. 18). Para o filósofo práxis é relação prática que se concretiza diretamente através de um "aperto de mão, um beijo, um diálogo, um golpe" ou, indiretamente, "por intermédio de algo: por exemplo, repartir um pedaço de pão; o pão não é pessoa, mas se reparte para a outra pessoa" (idem ibdem).

Paulo Freire, por sua vez, na "Pedagogia do Oprimido", ascende a concepção dusseliana afirmando que os humanos como seres da práxis, "são seres do quefazer", sujeitos que possuem a capacidade não só de conhecer o mundo, mas de transformá-lo. Sob essa perspectiva, o mundo passa de mero suporte e se torna espaço de reflexão e de ação, palco da práxis humana, e, "na razão mesma em que o quefazer é práxis, todo fazer

*DOI - 10.29388/978-65-86678-84-0-0-f.173-194 
do quefazer tem de ter uma teoria que necessariamente o ilumine. 0 quefazer é teoria e prática. É reflexão e ação" (FREIRE, 2005, p. 141).

Seguindo a trilha aberta por essa concepção epistemológica, faz-se possível afirmar que é na relação direta entre as pessoas ou na convivência entre elas que surge o diálogo como mediação das reflexões sobre o mundo e sobre a vida que dele emerge. Dessa articulação, como mostra a figura 1, são produzidos conhecimentos capazes de transformar o mundo da vida de quem, sob a lógica da totalidade vigente ${ }^{1}$, é negado em sua humanidade suprema, é roubado, humilhado, desonrado, violado, é destruído como "o outro termo da relação face-a-face" (DUSSEL, 1987, p. 29).

Figura 1. Diagrama que forma o processo do conhecimento enraizado a partir da concepção dusseliana e freirena de práxis. Fonte: Elaboração da autora.

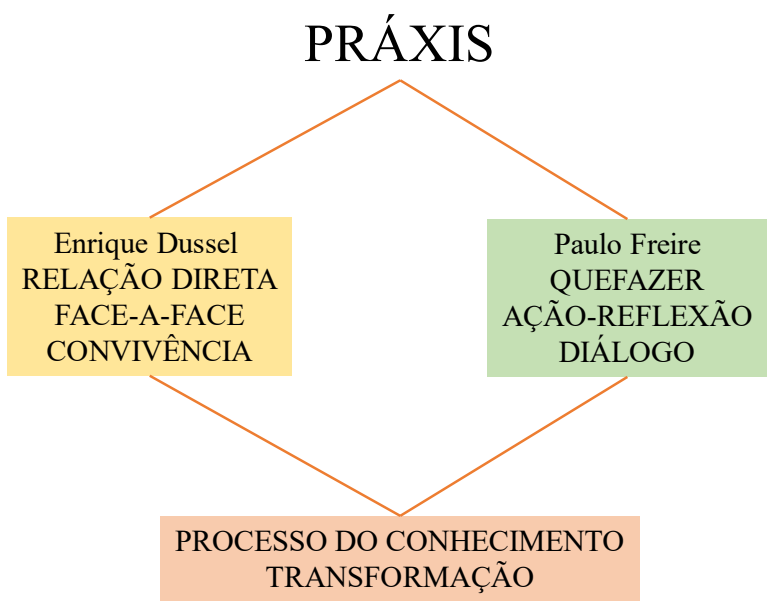

Fonte: Elaboração da autora

\footnotetext{
${ }^{1} \mathrm{~A}$ totalidade - categoria fundamental da Filosofia da Libertação - é o mundo ou o horizonte cotidiano do qual fazemos parte, onde vivemos (DUSSEL, 1977). O mundo, assim, é uma totalidade instrumental, carregado de sentido. Nele, encontram-se todos os entes, as coisas que nos rodeiam caoticamente. Dussel (1977) explica que o mundo não diz respeito ao cosmos como totalidade de coisas reais, mas de um conjunto de entes com sentido. Sem o ser humano o mundo não seria mundo, mas cosmos, pois é ele que confere sentido às coisas tornando o mundo uma realidade cósmica. "Em nossa sociedade", afirma o autor, "a totalidade do ser se fundamenta no valor, no capital. Desde o fundamento do capital se desdobra o mundo como totalidade concreta, histórica" (DUSSEL, 1977, p. 37, tradução minha, apud ALMEIDA, 2018, p. 53).
} 
A possibilidade da afetação da práxis no campo da educação, consequentemente, impacta o processo de produção enraizada de conhecimentos constituído por pessoas que, seja na escola de ensino básico, na universidade, nos movimentos populares ou em outros espaços educativos que se propõem críticos e transformadores, são privadas da relação face-a-face que, em outras palavras, resume-se à própria condição de sermos pessoas ${ }^{2}$. Isso quer dizer que, são impedidas de ser. Logo, também, são alienadas do quefazer da libertação, ficando à margem do processo reflexivo que se impõe sobre a construção da ação libertadora ${ }^{3}$.

A partir dessa epistemologia, olhar para o ensino remoto e para a $\mathrm{EaD}$ como solução estratégica para a educação brasileira, agenda que se fortalece no contexto de difusão planetária da COVID-19, torna-se tarefa necessária e urgente, uma vez que, "sem renda, vivendo o estresse, o sofrimento, a dor, a humilhação de sequer lograr alimentos", as famílias não têm "condições de assegurar, privadamente, espaços e tempos adequados à aprendizagem" (COLEMARX, 2020, p. 7).

A Educação do Campo - no âmbito do movimento social, da escola do campo e no seio das Licenciaturas em Educação do Campo (LEdoC's ${ }^{4}$ - é

\footnotetext{
${ }^{2}$ De acordo com Dussel (1987, p. 19): “Os extremos da "relação" prática são pessoas. O que é ser pessoa? Alguém é pessoa, estritamente, só e quando está na relação da práxis. Uma pessoa é pessoa só quando está ante outra pessoa ou pessoas. Quando está só perante a natureza cósmica, de certo modo deixa de ser pessoa. [...]. Quando estou com meu rosto frente ao rosto do outro na relação prática, na presença de práxis, ele é alguém para mim e eu sou alguém para ele, o "face-a-face" de duas ou mais pessoas é ser pessoa. [...] Frente a frente, pessoa a pessoa é a relação prática de proximidade entre pessoas como pessoas é que constitui o outro como "próximo" (próximo, vizinho, alguém), como outro; e não como coisa, instrumento, mediação. A práxis então, na atualização da proximidade, da experiência de ser próximo para o próximo, de construir o outro como pessoa, como fim de minha ação e não como meio: respeito infinito"

3"Não é possível à liderança tomar os oprimidos como meros fazedores ou executores de suas determinações; como meros ativistas a quem negue a reflexão sobre o seu próprio fazer. Os oprimidos, tendo a ilusão de que atuam, na atuação da liderança, continuam manipulados exatamente por quem, por sua própria natureza, não pode fazê-lo" (FREIRE, 2005, p. 142).

${ }^{4} \mathrm{O}$ oferecimento da Licenciatura em Educação do Campo (LEdoC) no escopo de cursos em nível de graduação de diversas Instituições de Ensino Superior (IES) brasileiras completou uma década em 2017. Esse tempo de existência possibilitou a realização de pesquisas analíticas vinculadas ao Programa Observatório da Educação em torno de diferentes dimensões das LEdoCs que, por sua vez, desdobraram reflexões mais abrangentes sobre as contribuições que as LEdoCs vêm proporcionando ao conjunto de políticas de formação de educadores/as (MOLINA, 2017), tendo em vista os princípios da Educação do Campo, matriz institucional dessa modalidade de educação de educadores/as. Nas LEdoC existentes em
} 
tomada aqui como foco central de análise, pois ela se apresenta na arena política como processo de resistência à educação e à escola neoliberal que "não sabe (e não pode) indicar qualquer alternativa" (idem ibdem) nesse cenário global catastrófico. Muito menos o governo brasileiro atual que sobrepuja a importância da continuidade da atividade econômica em detrimento da manutenção da dignidade da vida e da própria existência de seus cidadãos socialmente mais vulneráveis.

É por esse caminho que o presente texto constrói seus argumentos que, apoiados também na experiência educativa militante da autora ${ }^{5}$, enfatiza que o momento urge, não por estratégias educativas rasas reproduzidas de fora e levadas a cabo pelo Poder Público em parceira com órgãos internacionais - como o Banco Mundial - e grupos empresariais - como o Facebook e a Microsoft -, cujos interesses recaem sobre parâmetros de eficiência e lucratividade excluindo "qualquer ideário pedagógico mais consistente" (SILVA, 2001, p. 295). A defesa que se faz é pelo fortalecimento de processos de construção enraizados de conhecimento que, mesmo sendo desenvolvidos remotamente, sejam capazes de se impor como barreira resistente à ameaça de morte da práxis educativa transformadora.

mais de 40 universidades públicas brasileiras, essa demanda tem sido concretizada a partir de uma matriz curricular que organiza os processos educativos por áreas do conhecimento. Na Universidade Federal de Viçosa (UFV), por exemplo, os conteúdos formativos estão organizados em 3 eixos denominados: Social; Político e Metodológico que, por sua vez, abrangem Ciências Sociais e Humanidades e Ciências da Natureza. Essa organização matricial contempla diversas disciplinas que tratam o trabalho e a vida no campo, a ecologia política e as ciências como física, matemática, química, biologia, estágio supervisionado, alternância e outras, que visam dar suporte a uma compreensão ampliada da realidade do país e do campo brasileiro. Esse conjunto interdisciplinar ganha com a aproximação do educador/a do campo à comunidade rural, aos movimentos sociais e aos espaços que acumulam experiências de educação pela alternância, a possibilidade de construir e fortalecer sua identidade como sujeito organicamente envolvido com as pautas do povo que necessita do conhecimento acadêmico também. Em síntese, essa prática de formação de educadores/as do campo pautada em princípios da Pedagogia da Alternância, valoriza a relação do estudante com o campo de trabalho e com a vida cultural das comunidades rurais perfazendo o que Silva (2012) denomina de Alternância Real.

${ }^{5} \mathrm{Em}$ início de carreira, entre 2005 e 2009, militei no movimento de Economia Solidária. Trabalhei de 2010 a 2018 com a População de Rua, desenvolvendo ações políticas e pesquisa acadêmica com esse público (ALMEIDA, 2011; ALMEIDA, 2014; ALMEIDA, 2018). Desde 2018 sou docente do Departamento de Educação da Universidade Federal de Viçosa no âmbito da Licenciatura em Educação do Campo. Foi no seio dessa trajetória de vida que fortaleci a concepção de educação aqui apresentada e é dela que emergiu a necessidade de tratar o tema desse ensaio. 


\section{EaD e educação do campo}

O debate em torno da Educação à Distância ou ensino remoto, como tem sido denominada durante o fechamento das instituições de ensino na pandemia da COVID-19, é amplo e complexo e, como não é o foco central desse texto, não será aprofundado de forma sistemática. O objetivo aqui, é trazer para o cerne do argumento - de que o que funda o processo de produção do conhecimento é a práxis ou o face-a-face com sujeitos historicamente excluídos -, uma visão crítica acerca dessa modalidade educativa que se impõe como alternativa eficiente à resolução dos problemas estruturais da educação em nosso país. Problemas que não originam com a disseminação do novo coronavírus, como pode parecer à mirada do senso comum, mas que se aprofundam e aceleram com ele.

A implementação da EaD no Brasil não é recente, data do início dos anos de 1900, e vem crescendo progressivamente desde a publicação do Decreto 5.622 de 19/12/2005 que revogou o Decreto 2.494/98 e regulamentou o Art. 80 da Lei de Diretrizes e Bases da Educação Nacional (LDB) de incentivo do Poder Público "ao desenvolvimento e à veiculação de programas de ensino à distância, em todos os níveis e modalidades de ensino, e de educação" (BRASIL, 1996, sem página). No Decreto, a EaD está definida como sendo:

[...] modalidade educacional na qual a mediação didático-pedagógica nos processos de ensino e aprendizagem ocorre com a utilização de meios e tecnologias de informação e comunicação, com estudantes e professores desenvolvendo atividades educativas em lugares ou tempos diversos (BRASIL, 2005, sem página).

A reboque dessa definição, vem uma das justificativas à crescente implementação da Educação à Distância, especialmente na Educação Superior em cursos de graduação e pós-graduação stricto e lato sensu, que essa é uma maneira rápida e efetiva para dar acesso àqueles/as que não tiveram ou não têm a possibilidade de participar de espaços educativos presenciais. Nessa perspectiva a EaD seria, então, uma ferramenta que atenderia plenamente os setores populacionais socialmente mais vulneráveis da sociedade, um instrumento inovador para a democratização do conhecimento. 
De fato, desde que a primeira e a segunda geração de educação não presencial surgiu no Brasil via correspondência e programas de televisão ${ }^{6}$, respectivamente, muito avanço houve nesse campo com a popularização da internet, do smartphone, dentre outros aparatos tecnológicos que abriram possibilidades que um sem número de pessoas, à margem do direito à educação, acessassem espaços de ensino e aprendizagem remotamente. No entanto, a abertura de possibilidades educativas não significa, necessariamente, a garantia do direito à educação, muito menos de uma educação verdadeiramente gratuita e de qualidade. E essa lacuna suscita questionamentos, tais como: direito a qual educação? Educar para que? Qual a concepção e a prática educativa que está em jogo nas entrelinhas do discurso oficial em defesa da Educação à Distância?

Debates em andamento vêm destacando não só imprecisões teóricoconceituais, abstrações e inversões ideológicas e equívocos de interpretação de dados estatísticos, mas também lacunas no discurso oficial sobre o EaD, entre as quais a omissão de fatos como: sua presença inexpressiva no cenário da educação superior da maioria dos países; o investimento, sobretudo pela Espanha, na produção e exportação de pacotes educacionais e de $\mathrm{EaD}$; e a diferença marcante entre o Brasil e outros países quanto ao grau de mercantilização já existente na educação superior. Juntos, esses aspectos levam os críticos dessa modalidade de ensino a concluir que ela será um "filão comercial extremamente pernicioso que aprofundará, em curto espaço de tempo, essa mercantilização da educação" (ADUSP, 2005) (PATTO, 2013, p. 306).

O advento da pandemia do COVID-19 e a necessária medida de isolamento social adotada em diversos países do mundo e no Brasil, impôs que as escolas e universidades de todo o território fechassem suas portas para as pessoas e para as práticas educativas presenciais, abrindo as janelas de oportunidade para que o projeto político e econômico da EaD e de aulas remotas tomassem conta, concretamente, do campo educativo brasileiro. 0 intuito não é de demonizar o uso das Tecnologias de Informação e Comunicação (TICs) no processo de produção do conhecimento que é inerente à práxis educativa, mas afastar as falsas soluções para o contratempo da suspensão das aulas e para os problemas estruturais da

\footnotetext{
${ }^{6}$ Instituto Universal Brasileiro e Telecurso 2000.
} 
educação, a fim de fortalecer o que é central ao debate na conjuntura mundial (COLEMARX, 2020).

\begin{abstract}
Não está em questionamento a relevância das tecnologias de informação e comunicação (TIC) para a vida social e, especificamente, para a educação. Ciência, arte e cultura são indissociáveis das tecnologias que, por isso, devem ser incorporadas no fazer escolar. Defende-se que, no século $\mathrm{XXI}$, o acesso à internet é um direito fundamental, a exemplo dos direitos, ainda não assegurados, à água potável, à rede de esgoto, à energia, ao transporte. Considerando as crianças e jovens, esse direito é ainda mais urgente e deve ser assegurado pelo Estado, por se tratar de um serviço de crucial relevância. Complementarmente, os meios tecnológicos para interação criativa na internet devem ser popularizados e assegurados para todos os estudantes, especialmente computadores portáteis de qualidade (COLEMARX, 2020, p. 8).
\end{abstract}

Para o Movimento de Educação do Campo, institucionalizado ${ }^{7}$ por meio de suas escolas de Educação Básica e Licenciaturas para formação de professore/as que atuam nos anos finais do Ensino Fundamental e no Ensino Médio, a demanda pelo acesso a meios tecnológicos diversos é imprescindível. O lema dessa luta é que os povos do campo, que são aqueles que vivem, trabalham e lutam pela terra - como quilombolas, ribeirinhos, povos da floresta, indígenas, camponeses, sertanejos, semterra, dentre outros -, historicamente destituídos do direito a esse bem fundamental à produção, reprodução e desenvolvimento da vida humana (DUSSEL, 1977), possam também gozar de educação pública estatal de qualidade, cultura, ciência e tecnologias capazes de promover sustentabilidade e manutenção da vida fora das cidades.

\footnotetext{
${ }^{7} A$ instituição de uma determinada demanda comunitária, seja em qual nível estiver, é compreendida por Enrique Dussel (2007) como a mediação da luta política empreendida por um grupo e também como a materialização ou o resultado dela. As instituições para esse autor, situam-se no nível específico da política. Elas se diferenciam de uma experiência ou contexto social a outro e, sob o modo como viemos organizando a vida em sociedade, são necessárias à concretização dos projetos dos grupos estratificados em classes sociais. De acordo com Dussel (2007) são as instituições que oferecem as condições às ações presentes e futuras no percurso da luta política, não se reduzindo somente a elas, mas se estendendo à constituição de outras estruturas que façam valer as demandas pautadas pelos grupos sociais.
} 
Impulsionada por esse Movimento, a concepção de educação - seja escolar ou não escolar - e do processo de produção do conhecimento que dela frutifica, não pode prescindir da práxis transformadora anteriormente qualificada, abrindo brechas à efetiva mercantilização da educação e à sua transformação em "mais um item da cultura de massa e da indústria cultural" (PATTO, 2013, p. 314) que é, aliás, uma das intencionalidades silenciada no discurso oficial sobre a Educação à Distância e ao ensino remoto em nosso país.

A concepção de história que perpassa os argumentos em defesa do EaD é claramente evolucionista: tudo se passa como se o processo histórico fosse uma sucessão natural e linear de estágios sucessivos. Os que defendem sem nenhum questionamento 0 progresso tecnológico, acreditam piamente que estamos no estágio científico da racionalidade humana, motivo pelo qual qualquer saber que não se atenha aos fatos é tido como filosofia vã adotada por retrógrados que se opõem à marcha do progresso. De costas para o passado, reféns do presente e concebendo o futuro como um admirável mundo novo gerado pelo avanço da ciência e da técnica, os que exaltam, sem mais nada, "as novas tecnologias de comunicação e informação" (SÃO PAULO, 2008), "a metodologia inovadora" (SÃO PAULO, 2009) e suas "formas alternativas e adequadas ao atual estágio tecnológico" (SÃO PAULO, 2007) deixam na penumbra as relações de poder vigentes em sociedades marcadas por desigualdades sociais congênitas, bem como os mecanismos sociais entre os quais a política educacional - que perpetuam esse estado de coisas por meio de reformas que em essência nada mudam. [...] As aulas de curta duração da Universidade Virtual mimetizam a nova relação com o tempo louvada na contemporaneidade e inviabilizam a educação como formação da inteligência e da sensibilidade. Submetida à compressão do tempo, a educação se afasta da reflexão não por mero erro técnico, mas por meio da invasão das instituições de ensino pela lógica produtivista. Enquanto as teorias críticas da sociedade moderna desvelam os mecanismos de controle incrustados na racionalidade técnica, as que louvam o mundo atual resignam-se à fragmentação, aderem às aparências, recusam as ferramentas teóricas que permitem desvelar o que subjaz às superfícies. A perda da temporalidade implica a perda de profundidade e de visão de totalidade: Estamos na era da revolução eletrônica? Então, bem-vindos os recursos eletrônicos, dizem 
explícita ou implicitamente os adeptos do tecnicismo educacional, alheios à relação entre tecnologia e poder (PATTO, 2013, p. 308).

O fato da Educação do Campo figurar há pouco mais de uma década como política de Estado representa uma importante vitória popular de quem se movimenta pela Reforma Agrária, e motivo de regozijo de todos/as que acreditam no poder do povo organizado em coletivos políticos e da educação como motor de transformação da realidade. Entretanto, dada a conjuntura global e nacional que estamos vivenciando, de uma sociedade cada vez mais dominada pelo capital, e, no caso particular de nosso país, em um momento político que realiza retrocessos drásticos não apenas no campo dos direitos sociais e políticos, mas também no próprio processo civilizatório, que se faz necessário avançar na agenda da Educação do Campo e suas formulações.

O que estamos enfrentando no campo da educação é a pauta da privatização da escola pública, o estreitamento curricular e formativo do ensino para testes, a Escola sem Partido e a efetiva expansão da EaD e do ensino remoto. Sem deixar de mencionar o fechamento de escolas públicas no campo e na cidade, a precarização e desvalorização generalizada do trabalho docente e a defesa midiática de uma diversidade que ironicamente vem sendo exterminada de maneira brutal, não só nas periferias urbanas, mas, sobretudo, no campo através de atentados homicidas e da violência do trabalho altamente precarizado imposto pelo capitalismo agrário.

Exemplo dessa realidade são os incontáveis assassinatos encomendados de lideranças políticas e outros/as lutadores/as pela Reforma Agrária em diversas regiões do país e as mortes prematuras de trabalhadores/as nas lavouras do latifúndio brasileiro. $O$ agronegócio, cada vez mais, deita suas garras perversas sobre os povos do campo e sobre a biodiversidade, contando com o apoio quase irrestrito do Governo por meio das bancadas congressistas da bíblia, do boi e da bala.

O Brasil e os demais países latino-americanos estão submetidos a pressões econômicas, políticas e sociais sem precedentes, colocando em nosso contexto, inclusive, a possibilidade do retorno do trabalho escravo com a ultraflexibilização da legislação trabalhista que inibe essa prática abominável. Isso quer dizer que, para enfrentá-la, interpõe-se o desafio de compreender profunda e criticamente suas raízes e motivações históricas e agir coerentemente, sem fraquejar frente aos momentos mais perniciosos de ataque de direitos. 
Roseli Caldart em muitos de seus textos e intervenções públicas como representante do setor de educação do Movimento Sem Terra (MST) explica que nosso problema é fruto de um capitalismo de autorreprodução destrutiva, que coloca em jogo a própria possibilidade de sobrevivência da humanidade. Ela destaca que essa previsão realista, haja vista a destruição de recursos naturais em escala crescente, expressa a maior contradição do capitalismo. Embora as crises cumulativas do sistema carreguem em seu interior, as possibilidades de superação que certamente as lutas populares ampliarão (CALDART, 2016), o que estamos presenciando, no momento de elaboração desse ensaio, é a disputa de poder entre grupos hegemônicos, frente ao perigoso sufocamento dos movimentos populares e de outras iniciativas de resistência à ordem vigente.

Tendo como base a análise e compreensão crítica sobre a conjuntura brasileira, latino-americana e mundial, é possível perceber o risco iminente que tais movimentos que disputam a terra, os alimentos, a cidade e outros direitos fundamentais, de morrerem pela perda da esperança sobre o avanço concreto de suas bandeiras de luta, além de sofrerem com o obscurecimento crescente da riqueza da cultura de seus povos. Exemplo disso, é o caso da continuidade do processo de institucionalização da Educação do Campo, fortemente ameaçada pelo fechamento massivo de escolas de ensino básico e da precarização das LEdoC's nas universidades públicas brasileiras, fatos que se aprofundam com a presença da EaD se fazendo cada dia mais concreta e de sujeitos que, em vez de estarem comprometidos em interpor barreiras resistentes a esse processo, resignam-se, abrindo a guarda para que esse caminho não tenha mais volta.

\section{A educação do campo como práxis de resistência e libertação}

O momento impõe às estruturas de poder político e coletivos organicamente envolvidos com a Educação do Campo, seja nas escolas de ensino básico, superior, nas Escolas Famílias Agrícolas (EFA's,), nas Casas Famílias Agrícolas (CFR's), nas comunidades rurais, nos movimentos sociais em prol da reforma agrária e pela educação como pilar fundamental dessa luta, a tarefa de continuar fortalecendo as potencialidades dessa 
modalidade educativa que tem nos princípios da Pedagogia da Libertação um de seus pilares fundamentais.

A organização do trabalho pedagógico próprio da constituição e manutenção da escola capitalista, divide a teoria da prática e separa a escola do mundo do trabalho (FREITAS, 2009). A estratégia de dicotomização dessas dimensões essenciais da experiência humana - teoria e prática - é justamente apartar do processo educativo, a reflexão em torno da produção da existência material dos sujeitos envolvidos neles. Essa separação teoria/prática, sujeito/objeto, trabalho intelectual/ trabalho manual no âmbito das instituições de ensino, seja em qual nível for, ocasiona a formação de sujeitos, ora como mão-de-obra, ora como gestores, a depender da posição que ocupam na sociedade e da escola que frequentam (pública ou privada).

No cerne desse processo dicotômico estão embutidos dois projetos de mundo e organização societária diferentes e antagônicos, sendo que o projeto capitalista concebe a educação como mecanismo de alienação da criticidade dos sujeitos e a escola como mediação para sua perpetuação infinita. Aliena, assim, professores/as, alunos/as e demais membros dessa comunidade, da compreensão crítica sobre a realidade e do protagonismo em ações transformadoras da mesma. A Educação à Distância e o ensino remoto, nesse contexto, convertem-se em instrumentais potentes de esvaziamento do real sentido da práxis educativa e da produção de conhecimentos capazes de inverter a ordem das coisas. Servem, assim, de maneira rápida e eficiente para formar uma massa de sujeitos despolitizados e incapazes de pensar e, muito menos, de solucionar os problemas mais urgentes da comunidade e da nação.

Porém, como é no seio da contradição capitalista que surgem os inéditos viáveis (FREIRE, 2005), uma das questões chave da Educação do Campo em contraponto à concepção de educação que visa a manutenção do status quo, é a articulação teoria prática como fundamento da organização do trabalho pedagógico - dentro e fora da sala de aula pautada em processos de ensino e aprendizagem contextualizados à realidade dos sujeitos envolvidos na práxis educativa. Esse princípio, advindo da teoria pedagógica da libertação, confronta diretamente a educação bancária (FREIRE, 2005) e é pilar fundamental da Educação do Campo e do fato dela ter insurgido no seio do movimento social de luta pela terra e não em uma plataforma virtual do governo em parceria com 
empresas privadas como é o caso da EaD e do principal ator por trás dela: o Todos pela Educação ${ }^{8}$.

Objetivando a formação de sujeitos lutadores pela reforma agrária e pela educação estatal pública de qualidade para a população historicamente alijada desse direito básico no meio rural, especialmente a partir dos anos finais do ensino fundamental e do ensino médio, a Educação do Campo afirma-se por meio de especificidades próprias dessa luta política, dos seus sujeitos em seus territórios, de onde e para o qual a empreendem.

A não dicotomização da teoria e da prática no contexto da Educação do Campo, parte da ideia de que as diversas práticas sociais construídas pelos sujeitos que nele vivem, de modo geral, e a escola como território educativo fundamental nesse contexto de vida, em especial, não podem se valer simplesmente da transmissão de conhecimentos organizados em conteúdos fragmentados, disciplinares e disciplinadores físicos e mentais dos educandos/as. Muito menos, utilizando para essa difusão, exclusivamente aulas remotas, especialmente em um momento em que os educandos/as, tanto no nível básico como superior, ainda não estão com as habilidades de disciplina e concentração plenamente desenvolvidas. Nem de metodologias de ensino que, acontecendo exclusivamente entre os muros da escola, desconsideram a riqueza das práticas sociais externas a ela, e acontecendo remotamente, destroem a possibilidade do face-a-face entre educadores/as e educandos/as, relação

\footnotetext{
${ }^{8 " E m}$ consonância com os organismos internacionais e formando aliados para mediar tais recomendações, o Todos Pela Educação (TPE) coordenou, no dia 8 de abril, reunião com a participação do Conselho Nacional de Educação, Undime e Consed e representantes do Banco Mundial. A justificativa foi a necessidade de discutir pontos centrais que iriam compor o documento regulatório da Medida Provisória no 934, que trata sobre a flexibilização do calendário letivo na educação básica, do cumprimento de 200 dias letivos para cumprimento de $800 \mathrm{~h}$ de aulas. Foi uma reunião aberta ao público, porém sem margem de discussão e nem a participação de setores acadêmicos, estudantis e sindicais. As regras já estavam definidas, de modo a fazer do TPE e seus aliados os supostos salvadores das crianças e jovens da classe trabalhadora expropriada e explorada, aqueles que mais sofreriam o impacto do isolamento social e do fechamento das escolas. Fiéis às recomendações dos organismos internacionais, prescreveram o uso de aulas remotas, disponibilizaram pacotes pedagógicos para o ensino à distância e buscam fechar parcerias com empresas de comunicação para conceder conexão de internet e laptops. Para que seus pacotes pedagógicos digitais possam ser considerados atividades curriculares, no referido documento serão conceituados como "ensino remoto", já que EaD é uma modalidade regulamentada e mais complexa (COLEMARX, 2020, p. 14).
} 
onde estão implicadas diversas questões que tornam o processo de produção do saber viável e original, enraizada.

É no campo configurado pela presença de um professor que fala diante de seus alunos e se expõe pessoalmente - pois não se limita à leitura de um texto previamente preparado - que se dá o fenômeno da transferência, primeiramente do professor que fala, e depois dos alunos, quando estes começam a falar e a ser ouvidos pelo professor (KUPFER, 2010). Mas definir a relação pedagógica com uma relação transferencial de dupla mão não significa defendê-la como uma relação de amor - como uma pedagogia do amor -, nem pregar o amor para eliminar a frieza, e isso por três motivos: porque essa pregação não é suficiente para mudar a ordem social que produz e reproduz a frieza; porque o amor não pode ser exigido em relações profissionalmente intermediadas, como o é a relação professor-aluno; porque, transformado em dever, ele faz parte da ideologia que perpetua a indiferença ao outro (ADORNO, 1995). No entanto, se a demanda de acolhimento mútuo é necessária à construção da relação professor-aluno - o que, de novo, exclui o ensino virtual como terreno propício ao convívio entre o professor e seus alunos nos termos em que o definimos aqui -, ela não é suficiente; é necessário um terceiro elemento que rompa essa relação e a remeta à dimensão simbólica. No caso da educação escolar, esse terceiro é o desejo de saber do aluno, sem o qual não se constrói o lugar do professor. Segundo Kupfer (2010), é a maneira especial com que o professor se relaciona com a matéria que escolheu, é seu estilo que desperta nos alunos o desejo de terem com o saber uma relação parecida, embora com o estilo próprio a cada um, sem o que seriam espelhos, robôs, clones do professor. Chauí (1980, p. 39) diz isso de outro modo: uma pedagogia centrada na consciência contraditória do professor e do aluno pressupõe "um professor que não tem modelos para imitar porque aceitou a contingência radical da experiência pedagógica" (PATTO, 2013, p. 313).

A Educação do Campo preconiza que sejam pensados espaços e tempos educativos libertadores - dentro e fora da escola e da sala de aula - que combinem as múltiplas dimensões de formação da pessoa, como o trabalho na terra ou a produção e reprodução das tradições culturais das comunidades rurais, por exemplo. Além da compreensão ampliada sobre o território camponês e do agronegócio que coexistem em conflito no contexto rural brasileiro. O ensino remoto, por meio das TICs, pode ser usada como estratégia 
pedagógica em momentos específicos da práxis educativa, desde que não seja fator de exclusão e, aos responsáveis pela organização e condução do processo educativo, cabe o papel crítico de perceber que essa ferramenta não dá conta da complexidade do que as escolas do campo e as Licenciaturas que formam seus educadores/as se propõem em termos de formação ominlateral ${ }^{9}$.

As escolas do campo, as LEdoC's e seus sujeitos, que nem sempre possuem trajetória de vida no meio rural, mas que se veem diante desse desafio, necessitam repensar a organização do trabalho pedagógico, bem como de toda a estrutura de gestão do espaço educativo, tendo em vista que a experiência concreta de quem vive no e do campo ou o "saber de experiência feito" (FREIRE, 2005) desses povos, é o ponto de partida da organização da práxis educativa e do processo de produção do conhecimento que objetiva a formação de sujeitos conscientes sobre seu lugar e seu papel no mundo.

Diante dessa exigência histórica, é que os envolvidos diretamente com a Educação do Campo, nos níveis básico e superior, não podem aceitar cegamente a $\mathrm{EaD}$ e seu uso irrestrito nos processos de formação já mencionados. Vale lembrar que, informação é substancialmente diferente de formação.

[...] é preciso ressaltar que a recusa à mentalidade tecnicista não é recusa radical à televisão como recurso educativo. Os próprios críticos dessa maneira de pensar destacam o potencial educativo da TV, mas, para evitar mal-entendidos, esclarecem a natureza desse potencial: a serviço das TVs educativas, ela contribui para a formação cultural ao veicular o melhor da produção espiritual nos campos da filosofia, das ciências e das artes, de modo a interessar o grande público. É por essa via que a TV pode concorrer - de modo importante, embora sempre restrito, porque inevitavelmente

\footnotetext{
${ }^{9}$ Omnilateral é um termo que vem do latim e cuja tradução literal significa 'todos os lados ou dimensões'. Educação omnilateral significa, assim, a concepção de educação ou de formação humana que busca levar em conta todas as dimensões que constituem a especificidade do ser humano e as condições objetivas e subjetivas reais para seu pleno desenvolvimento histórico. Essas dimensões envolvem sua vida corpórea material e seu desenvolvimento intelectual, cultural, educacional, psicossocial, afetivo, estético e lúdico. Em síntese, educação omnilateral abrange a educação e a emancipação de todos os sentidos humanos, pois os mesmos não são simplesmente dados pela natureza. O que é especificamente humano, neles, é a criação deles pelo próprio homem (Mészáros, 1981, p. 181) (FRIGOTTO, 2010, p. 267).
} 
superficial e de fora para dentro - para a abertura de "uma brecha na barreira do conformismo". Mas, mesmo nesse caso, ela não forma: "o conceito de informação é mais apropriado à TV do que o conceito de formação" (ADORNO, 1995, p. 79). De caráter essencialmente informativo e documentário, ela não tem como formar para a experiência do pensamento. Evidentemente, os conteúdos e métodos da educação presencial também se podem prestar à ideologização e resultar em mera aceitação do estabelecido, mas a reversão profunda disso - que se faz de dentro para fora - só pode acontecer numa instituição educativa real, ou seja, habitada por professores e alunos cujas relações face a face tecem a vida institucional (PATTO, 2013, p. 312).

É momento de, mais que nunca, repensar a educação, a escola e a universidade como um todo e não só seus elementos constitutivos isoladamente. A ideia que se desprende do aqui exposto, é que a organização da tarefa do educador/a e os modos como os conteúdos são trabalhados nos espaços-tempos educativos contextualizados pela vida no campo e na cidade, incorporem os movimentos da realidade e os convertam em conteúdos formativos. E que os processos educativos dentro e fora da escola recorram a modelos interdisciplinares de ensino e aprendizagem, de maneira a problematizar a situação ou "o aqui e o agora" de homens e mulheres, jovens e adultos no e com o mundo, a fim de que seja possível aprofundar a consciência da realidade das "situações limite" e do papel transformador dos povos condenados da Terra.

\section{Considerações em torno de uma agenda de reflexão e luta no campo da educação}

A Educação do Campo no Brasil é demanda e resultado da luta política empreendida pelos povos que vivem, trabalham, se educam e lutam na e pela terra. Práxis da qual toda a humanidade depende para se manter de pé. Sua origem e pressupostos teórico-metodológicos estendem suas raízes a uma concepção de mundo, de educação e de escola não capitalistas que têm nos movimentos sociais brasileiros e nas culturas populares, especialmente advindas dos povos do campo, suas principais referências. Afirmo também que tem, em Paulo Freire e Enrique Dussel, suportes teóricos que não abrem mão da afirmação de que, as vítimas do 
mundo, e somente elas, serão capazes de constituir uma comunidade política anti-hegemônica com validez crítica. E como atores históricos lutam pelo reconhecimento de novos direitos, emergirão como construtores de outra universalidade (desde a diferença) por meio da práxis de libertação que funda processos revolucionários de construção de conhecimentos (ALMEIDA, 2018).

Outras modalidades de educação desenvolvidas com a intenção de que o povo se tornasse sujeito de um processo de transformação, existiram ao longo do tempo em outros momentos da história e em diversos países do mundo, como a prática educativa disseminada por movimentos anarquistas e comunistas desde 1900 em nosso país. No Brasil, a Educação do Campo se apresenta como um movimento cultural de transformação social, não uma plataforma governamental, mas como parte dos movimentos de cultura popular dirigidos basicamente às populações rurais. Ela foi concebida como uma estratégia de superação da educação rural tradicional que, basicamente, reproduzia a educação urbana deixando de lado toda a especificidade das comunidades rurais, desqualificando-as como produtoras de saber e de cultura legítima.

A práxis educativa-política promovida pelos movimentos sociais protagonizados pelos sujeitos do campo, cujos pressupostos teóricosmetodológicos embasaram e seguem apoiando a constituição e fortalecimento da Educação do Campo brasileira, preconiza a necessidade de construção de um projeto popular para o Brasil que deve ser protagonizado pelo povo organizado autonomamente, a fim de assumir compromissos em torno: da soberania que rompa com a dependência externa; da solidariedade que rompa com a desigualdade interna; do desenvolvimento contrário à tirania do capital financeiro; da sustentabilidade que busque novos estilos de desenvolvimento socialmente justos e ecologicamente viáveis e da democracia popular que mire a construção de um sistema político participativo (BENJAMIN, CALDART, 2000).

Nosso país necessita de mais do que alterações na política econômica. Precisa construir outro sistema de poder que seja democrático e, para tanto, o projeto popular a ser construído pelos movimentos sociais ligados fortemente às culturas camponesas e de suas lutas políticas, devem apontar a democratização: da terra por meio da reforma agrária; da riqueza, com a ampliação de acesso ao crédito e aumento dos financiamentos ao investimento produtivo prioritário, além do controle 
financeiro pelo Estado Nacional; da informação por meio de rádios, TV's e redes públicas que fiquem sob o controle da sociedade e que transmitam conteúdos melhores e, por fim, a democratização da cultura com escolas públicas estatais de qualidade no local de vida dos sujeitos do campo e da cidade, a disseminação da aprendizagem que vise a formação integral humana e a valorização irrestrita dos/as professores/as e demais profissionais ligados à disseminação dessa cultura sui generis.

Só mesmo o fortalecimento dos movimentos de resistência por uma educação crítica e transformadora, aliados a outras disputas - por terra, renda, poder político, econômico, jurídico, etc. - é que darão conta de levar adiante o planejamento e o alcance desse projeto popular. E isso não poderá ser feito mediante a destruição do que o texto trouxe na abertura de sua argumentação: da concepção epistemológica que delineia o campo da práxis educativa libertadora e a produção enraizada de conhecimentos capazes de apoiar essa luta política. Para isso, como autora do presente ensaio, não poderia evadir da responsabilidade de apontar como educadora popular e formadora de professores/as do campo algumas propostas de ações factíveis a serem empreendidas em momentos de aprofundamento de crises, como a pandemia da COVID-19, que serve de pretexto para que uma agenda econômica e política privatista para a educação brasileira, seja amplamente concretizada.

Como a $\mathrm{EaD}$ e o ensino remoto não são propostas estritamente vinculadas à pandemia, mas um projeto de longa data e com raízes profundas, urge organizar uma agenda de estudo e ações sobre seus impactos na educação, buscando conhecer e acompanhar a realidade de sua implementação no campo brasileiro. As propostas que seguem direcionam-se, em um primeiro momento, a docentes das Instituições de Ensino Superior, da Educação Básica e a todas as pessoas diretamente envolvidas com o Movimento da Educação do Campo, em parceria com outras organizações e grupos populares que possam somar suas pautas em prol da defesa da concepção e da práxis educativa aqui qualificada e do planejamento e execução do projeto popular mencionado. As propostas são as seguintes:

I. Realização de escuta permanente, sistemática e qualificada dos educandos/as do campo e suas comunidades, acerca das condições materiais de vida (antes, durante e pós-pandemia), principalmente no que 
tange às: situações de moradia; trabalho e renda; alimentação, vestuário ${ }^{10}$, saúde física e mental;

II. Criação de redes de apoio e solidariedade que possam atender as demandas mais urgentes identificadas a partir da escuta anteriormente descrita;

III. Desenvolvimento de pesquisas quantitativas e qualitativas em torno dos impactos da EaD sobre as escolas e Licenciaturas em Educação do Campo, desde a compreensão dos educandos/as e educadores/as a respeito dessa modalidade educativa, até as reais condições de acesso e desenvolvimento das atividades pedagógicas remotas;

IV. Planejamento e execução de ações (manifestos, abaixo-assinados, vídeos, lives, filmes, podcasts, etc) que ofereçam resistência à entrada massiva e arbitrária de aulas remotas nas instituições de ensino ligadas à Educação do Campo. Essa ação será fortalecida a partir de diálogo e envolvimento de diversos coletivos em luta pela educação, sejam nas escolas, universidades, movimentos sociais e outros;

V. Intensificação dos processos de formação dos sujeitos ligados à Educação do Campo, com a criação de espaços de estudo, fomento ao desenvolvimento de pesquisas e outras atividades que façam jus ao fortalecimento da concepção de educação que deve ser levada a cabo pelos sujeitos, sem relativizações que a enfraqueçam teórica e praticamente;

VI. Criação e disponibilização de espaços remotos para disseminação da arte, da ciência e da cultura aos educadores/as e educandos/as das escolas e Licenciaturas em Educação do Campo e suas comunidades que possam e queiram acessar, sem que haja obrigatoriedade e a contabilização de carga horária letiva com a participação neles;

VII. Intensificação da luta pelo acesso dos povos do campo às Tecnologias de Comunicação e Informação e à internet livre e de qualidade, compreendendo que esse é um direito inalienável que deve ser garantido a

\footnotetext{
10“[...] não há gozo e alegria de comer, morar, vestir (como proteção contra o frio), etc., sem a coisa ou objeto produzido que nega a necessidade. Esta coisa, porém, este objeto, produto, é fruto do trabalho e se distribui segundo as instituições sociais. No capitalismo se possui o objeto do consumo antecipadamente pago em dinheiro. Se alguém tem fome mas não dinheiro, ficará com sua fome, porque ninguém pode auxiliá-lo. 0 sem-dinheiro não nega por isso sua sensibilidade (sua fome); deve suportá-la como injustiça ética - embora a moral social vigente a ninguém possa culpar. $O$ alimento, a casa e a roupa são objetos de consumo, mas além disso "sinais" de bondade quando são produtos do serviço, da justiça, da práxis libertadora" (DUSSEL, 1987, p. 78-79).
} 
todos igualmente e não usado como arma de monopolização do poder e do saber.

\section{Referências}

ALMEIDA, Sara Ferreira de. 0 retorno da população em situação de rua à educação escolar: entre dificuldades e possibilidades. 2011. $182 \mathrm{f}$. Monografia (Especialização em Educação de Jovens e Adultos) - Núcleo de Investigação e Ação Social e Educativa (NIASE/UFSCAR). Departamento de Teorias e Práticas Pedagógicas, Universidade Federal de São Carlos, São Carlos, 2011.

ALMEIDA, Sara Ferreira de. A prática social - Viver no mundo da rua - e seus processos educativos. 154f. Dissertação (Mestrado em Educação) Universidade Federal de São Carlos, Centro de Educação e Ciências Humanas, Programa de Pós-Graduação em Educação, São Carlos/SP, 2014.

ALMEIDA, Sara Ferreira de. Andarilhos da esperança: estudo sobre a luta política impulsionada pela vida na rua e seus processos educativos sistematizada na experiência do Fórum da População de Rua de São Carlos/SP entre 2016 e 2017. 375f. Tese (Doutorado em Educação) Universidade Federal de São Carlos, Centro de Educação e Ciências Humanas, 2018.

BENJAMIN, César; CALDART, Roseli Salete. Projeto Popular e escolas do campo: por uma educação básica do campo. Brasília: Articulação Nacional por uma Educação Básica do Campo, 2000.

BRASIL. Lei de Diretrizes e Bases da Educação Nacional. Lei no 9.394, de 20 de dezembro de 1996. Disponível em:

http://www.planalto.gov.br/ccivil_03/leis/19394.htm. Acesso em: maio de 2020.

BRASIL. Decreto no 5.622, de 19 de dezembro de 2005. Regulamenta o art. 80 da Lei no 9.394, de 20 de dezembro de 1996, que estabelece as diretrizes e bases da educação nacional. Disponível em: http://portal.mec.gov.br/sesu/arquivos/pdf/portarias/dec5.622.pdf. Acesso em: maio de 2020. 
CALDART, Roseli Salete. Trabalho, agroecologia e educação politécnica nas escolas do campo. Para publicação em: PIRES, João Henrique, NOVAES, Henrique T., MAZIN, Angelo e LOPES, Joyce (orgs). Questão agrária, cooperação e agroecologia, vol. III. São Paulo: Outras Expressões, no prelo. 2016.

COLEMARX. Em defesa da educação pública comprometida com a igualdade social: porque os trabalhadores não devem aceitar aulas remotas. Rio de Janeiro, 2020. Disponível em:

http://www.colemarx.com.br/wp-content/uploads/2020/04/Colemarxtexto-cr\%C3\%ADtico-EaD-2.pdf. Acesso em: maio de 2020.

DAMKE, Ilda Righi. O processo do conhecimento na Pedagogia da Libertação: as ideias de Freire, Fiori e Dussel. Petrópolis/RJ: Vozes, 1995.

DUSSEL, Enrique. Filosofia de la liberación. 1. ed. México: EDICOL, 1977. 234 p. Disponível em: http://www.enriquedussel.com/libros.html\#. Acesso em: abr. 2012.

DUSSEL, Enrique. Ética Comunitária. Petrópolis/RJ: Vozes, 1987.

DUSSEL, Enrique. 20 teses de política. São Paulo: Expressão Popular, 2007

FREIRE, Paulo. Pedagogia do oprimido. Rio de Janeiro: Paz e Terra, 2005.

FREITAS, Luiz Carlos. Crítica da organização do trabalho pedagógico e didática. Campinas: Papirus, 2009.

FRIGOTTO, Gaudêncio. Educação omnilateral. In: CALDART, Roseli Salete; PEREIRA, BRASIL, Isabel; ALENTEJANO, Paulo; FRIGOTTO, Gaudêncio (Orgs.).

Dicionário da Educação do Campo. Rio de Janeiro, São Paulo: Escola Politécnica de Saúde Joaquim Venâncio, Expressão Popular, 2012, p. 267274.

MOLINA, Mônica Castagna. Contribuições das Licenciaturas em Educação do Campo para as políticas de formação de educadores. Educ. Soc., Campinas, v. 38, no. 140, p.587-609, jul-set., 20172017. 
PATTO, Maria Helena Souza. O ensino a distância e a falência da educação. Educ. Pesqui., São Paulo, v. 39, n. 2, abr./jun. 2013, p. 303-318

SILVA, Franklin Leopoldo e. Reflexão sobre o conceito e a função da universidade pública. Estudos Avançados, São Paulo, v. 15, n. 42, p. 295-304, 2001.

SILVA, Lourdes Helena da. As Experiências de formação de jovens do campo: alternância ou alternâncias? Edição Revisada. 02. ed. Curitiba-PR: Editora CRV, 2012. 